\title{
Ustekinumab for the treatment of psoriatic arthritis: an update
}

This article was published in the following Dove Press journal:

Clinical, Cosmetic and Investigational Dermatology

2 September 2014

Number of times this article has been viewed

\section{Parastoo Davari \\ Michael S Leo \\ Faranak Kamangar \\ Nasim Fazel \\ Department of Dermatology, University of California, Davis, CA, USA}

Correspondence: Faranak Kamangar Department of Dermatology, University of California, 330 I C Street - Suite I400, Davis, CA 95816, USA

Email fkamangar@gmail.com

\begin{abstract}
Psoriatic arthritis occurs in $30 \%$ of psoriasis patients, and the treatment can be challenging in some patients. Recently, the US Food and Drug Administration approved ustekinumab, a fully human monoclonal antibody, for the management of psoriatic arthritis. In this article, we review large-scale randomized clinical trials addressing the efficacy and safety profile of ustekinumab for the treatment of psoriatic arthritis.
\end{abstract}

Keywords: psoriatic arthritis, psoriasis, ustekinumab

\section{Introduction}

Psoriatic arthritis (PsA) is an incapacitating seronegative arthritis that occurs in up to $30 \%$ of patients with psoriasis. ${ }^{1-3}$ PsA is more prevalent among patients with relatively severe psoriasis. Risk factors for a more severe course of arthritis include initial presentation at an early age, female sex, polyarticular involvement, genetic predisposition, and radiographic signs of the disease early on. ${ }^{3}$ The following classification has been outlined by Moll: ${ }^{4}$ mono- and asymmetric oligoarthritis (including the classic involvement of the whole digit referred to as the "sausage" digit), arthritis of the distal interphalangeal joints, rheumatoid arthritis-like presentation, arthritis mutilans, and spondylitis and sacroiliitis.

In recent years, among biologic agents, $\mathrm{TNF} \alpha$ inhibitors have been a mainstay for the treatment of PsA. ${ }^{5}$ Although these agents can remarkably improve the clinical manifestations of PsA and prevent radiographic joint damage, 5,6 a number of patients fail to respond to TNF $\alpha$ inhibitors, experience recurrence, or develop resistance to these therapies. The introduction of ustekinumab and similar drugs was therefore considered an advancement in the management of emergent or refractory PsA. In 2008 and 2009, ustekinumab was approved by the European Medicines Agency (EMA) and the US Food and Drug Administration (FDA), respectively, for the treatment of moderateto-severe plaque psoriasis in adult patients. In September 2013, the EMA and FDA also approved ustekinumab for the treatment of PsA. In this article, we review the pharmacodynamics, pharmacokinetics, efficacy, and safety profile of ustekinumab for the management of PsA.

\section{Pharmacodynamics and pharmacokinetics}

Ustekinumab is a fully human immunoglobulin $\mathrm{G}_{1}$ monoclonal antibody against the shared p40 subunit of IL-12 and IL-23, thereby preventing IL-12 and IL-23 from binding to the receptor chain IL-12Rb1 to trigger downstream signaling pathways. ${ }^{7}$ The pathways 
activated by IL-12 and IL-23 are well established, and are linked to the pathogenesis of psoriasis. It has been demonstrated that dendritic cells and macrophages can overexpress IL-12 and IL-23 cytokines in psoriatic lesions. ${ }^{8}$ IL-12 is a proinflammatory cytokine involved in differentiating naïve $\mathrm{T}$ cells into T-helper (Th)- 1 cells and producing IFN $\gamma$ and TNFo. ${ }^{9}$ IL-23 enables the expansion of Th17-positive cells, which produce IL-17 and other cytokines. ${ }^{10,11}$ Studies support the fundamental role of IL-23 and Th-17 in the pathogenesis of psoriasis. ${ }^{12,13}$ In addition, Filer et al noted that variations in the IL-23 receptor and IL-12B single nucleotide polymorphisms are associated with susceptibility to both psoriasis and PsA. ${ }^{14}$ Although psoriasis and PsA have been recently shown to have similar susceptibility loci and considerable genetic overlap, ${ }^{15}$ it is still not clear that both conditions respond equally well to ustekinumab.

The pharmacokinetic properties of ustekinumab in human patients have been evaluated. Zhu et al reported that the mean values for apparent clearance, apparent volume of distribution, and absorption-rate constant were similar among PsA patients and patients with mild-to-severe psoriasis. ${ }^{16}$ Importantly, the patient's body weight and the levels of antibodies against ustekinumab significantly affected the pharmacokinetic properties, ${ }^{16}$ although the significance of antiustekinumab antibodies has not yet been determined. ${ }^{17}$ Other variables, such as age, sex, disease duration, and baseline Psoriasis Area and Severity Index (PASI) score showed no remarkable effects on the volume of distribution or clearance values. ${ }^{16}$ Indeed, in a population-based pharmacokinetic analysis, there were no apparent changes in pharmacokinetic properties among elderly patients. ${ }^{7}$ Also, it has been shown that the clearance of ustekinumab was not changed by concurrent administration of methotrexate, nonsteroidal anti-inflammatory drugs, oral corticosteroids, or prior exposure to anti-TNF $\alpha$ agents in PsA patients. ${ }^{7}$

\section{Efficacy}

Multiple clinical trials have demonstrated the beneficial efficacy of ustekinumab in psoriasis patients. Kauffman et al reported that $67 \%$ of patients treated with ustekinumab showed a PASI 75 over the course of a 16-week Phase I study. ${ }^{18}$ In another Phase I study, compared to no symptom improvement for the placebo group, $76 \%$ of patients treated with ustekinumab achieved 75\% improvement in PASI score. ${ }^{19}$ In a Phase II dose-ranging randomized clinical trial (RCT), PASI 75 was achieved by week 12 with a distinct dose-dependence: $52 \%$ of patients treated with a single $45 \mathrm{mg}$ dose, $59 \%$ of patients treated with a single
$90 \mathrm{mg}$ dose, $67 \%$ of patients treated with $45 \mathrm{mg}$ doses every 4 weeks, and $81 \%$ of patients treated with $90 \mathrm{mg}$ doses every 4 weeks. ${ }^{20}$ Over the same time period, only $2 \%$ of placebo-treated patients achieved PASI 75. In the phase III PHOENIX (Psoriasis Followed by Long-Term Extension) 1 trial with 766 patients, $67.1 \%$ of patients treated with $45 \mathrm{mg}$ ustekinumab and $66.4 \%$ of patients treated with $90 \mathrm{mg}$ ustekinumab achieved PASI 75 after 12 weeks, whereas $3.1 \%$ of the placebo-treated patients achieved PASI $75 .{ }^{21}$ PHOENIX 2 showed comparable results in 1,230 patients. PASI 75 was achieved in $66.7 \%$ of patients receiving ustekinumab $45 \mathrm{mg}$, $75.7 \%$ receiving ustekinumab $90 \mathrm{mg}$, and $3.7 \%$ receiving placebo. ${ }^{22}$ The Phase III ACCEPT (Active Comparator [CNTO1275/Enbrel] Psoriasis Trial) showed PASI 75 in $67.5 \%$ of the group treated with $45 \mathrm{mg}$ ustekinumab, $73.8 \%$ of the group treated with $90 \mathrm{mg}$ ustekinumab, and $56.8 \%$ of the group treated with $50 \mathrm{mg}$ etanercept. ${ }^{23}$ Finally, PEARL (Efficacy and Safety of Ustekinumab for the Treatment of Moderate-to-Severe Psoriasis: A Phase III, Randomized, Placebo-Controlled Trial in Taiwanese and Korean Patients) evaluated an Asian population of psoriasis patients, and found PASI 75 in $67.2 \%$ of ustekinumab-treated patients, compared to only $5.0 \%$ of placebo-treated patients. ${ }^{24}$

Thus far, there have been no Phase I clinical trials investigating the dose response or safety profile of ustekinumab for treating PsA. Support for conducting later-stage clinical trials for PsA efficacy was based on Phase I evidence for efficacy reported from clinical trials for the treatment of moderate-to-severe plaque psoriasis. ${ }^{17,18}$ One Phase $\mathrm{II}^{25}$ and two Phase III ${ }^{26,27}$ large-scale RCTs investigated the efficacy and safety of ustekinumab in the management of PsA. The results of these trials were published recently, and are summarized in Table 1.

The first study was a randomized, multicenter, doubleblind, placebo-controlled, crossover Phase II trial that was published in $2009 .{ }^{25}$ In this study, 146 patients with active PsA were recruited at multiple clinical sites in Europe and North America, with inclusion criteria consisting of three or more swollen joints, three or more tender joints, and either a C-reactive protein (CRP) level of at least $15 \mathrm{mg} / \mathrm{L}$ or a minimum of 45 minutes of daily morning stiffness. Patients were also required to have at least one active skin psoriatic lesion of $2 \mathrm{~cm}$ or larger. Patients were randomly assigned to two treatment groups. Patients in the first group received weekly subcutaneous ustekinumab (90 or $63 \mathrm{mg}$ ) for 4 weeks, followed by placebo at weeks 12 and 16, and patients in the second group received placebo every week for 4 weeks, followed by ustekinumab (63 mg) at weeks 12 and 16 . 
Table I A summary of the main outcomes presented in Phase II and III trials comparing ustekinumab to placebo

\begin{tabular}{|c|c|c|c|c|c|c|c|}
\hline \multirow{3}{*}{$\begin{array}{l}\text { Outcome } \\
\text { measure }\end{array}$} & \multirow[t]{3}{*}{ Study } & \multirow{3}{*}{$\begin{array}{l}\text { Concurrent } \\
\text { therapy }\end{array}$} & \multicolumn{3}{|c|}{ Treatment groups } & & \multirow[t]{3}{*}{$P$-values } \\
\hline & & & Placebo & & Ustekinumab & & \\
\hline & & & & & 63 or $90 \mathrm{mg}$ & & \\
\hline \multirow{11}{*}{$\begin{array}{l}\text { ACR } 20 \\
\text { response }\end{array}$} & Gottlieb et $\mathrm{a}^{25}$ & All patients & $32 / 76(42 \%)$ & & $10 / 70(14 \%)$ & & 0.0002 \\
\hline & & & Placebo & Ustekinumab & Ustekinumab & Combined & \\
\hline & & & & $45 \mathrm{mg}$ & $90 \mathrm{mg}$ & ustekinumab & \\
\hline & Mclnnes et $\mathrm{al}^{26}$ & All patients & $47 / 206$ (22.8\%) & $87 / 205$ (42.4\%) & $101 / 204$ (49.5\%) & I88/409 (46.0\%) & $\begin{array}{l}<0.000 \text { I for all comparisons } \\
\text { versus placebo }\end{array}$ \\
\hline & & $\begin{array}{l}\text { With MTX } \\
\text { treatment }\end{array}$ & $25 / 96(26.0 \%)$ & 43/99 (43.4\%) & $46 / 101$ (45.5\%) & $89 / 200$ (44.5\%) & \\
\hline & & $\begin{array}{l}\text { Without MTX } \\
\text { treatment }\end{array}$ & $22 / 110$ (20.0\%) & $44 / 106$ (4I.5\%) & $55 / 103$ (53.4\%) & $99 / 209$ (47.4\%) & \\
\hline & Ritchlin et $\mathrm{al}^{27}$ & All patients & $21 / 104$ (20.2\%) & 45/I03 (43.7\%) & $46 / 105$ (43.8\%) & $91 / 208$ (43.8\%) & $\begin{array}{l}<0.001 \text { for all comparisons } \\
\text { versus placebo }\end{array}$ \\
\hline & & $\begin{array}{l}\text { With MTX } \\
\text { treatment }\end{array}$ & I4/49 (28.6\%) & $27 / 54(50.0 \%)$ & $21 / 52$ (40.4\%) & $48 / 106$ (45.3\%) & \\
\hline & & $\begin{array}{l}\text { Without MTX } \\
\text { treatment }\end{array}$ & 7/55 (I2.7\%) & I8/49 (36.7\%) & $25 / 53(47.2 \%)$ & $43 / 102(42.2 \%)$ & \\
\hline & & & Placebo & & Ustekinumab & & \\
\hline & & & & & 63 or $90 \mathrm{mg}$ & & \\
\hline \multirow{8}{*}{$\begin{array}{l}\text { PASI } 75 \\
\text { response }\end{array}$} & Gottlieb et $\mathrm{al}^{25}$ & All patients & $3 / 55(5 \%)$ & & $33 / 63$ (52\%) & & $<0.0001$ \\
\hline & & & Placebo & $\begin{array}{l}\text { Ustekinumab } \\
45 \mathrm{mg}\end{array}$ & $\begin{array}{l}\text { Ustekinumab } \\
90 \mathrm{mg}\end{array}$ & $\begin{array}{l}\text { Combined } \\
\text { ustekinumab }\end{array}$ & \\
\hline & Mclnnes et $\mathrm{al}^{26}$ & All patients & $16 / 146$ (11.0\%) & $83 / 145$ (57.2\%) & $93 / 149$ (62.4\%) & I76/294 (59.9\%) & $\begin{array}{l}<0.000 \text { I for all comparisons } \\
\text { versus placebo }\end{array}$ \\
\hline & & $\begin{array}{l}\text { With MTX } \\
\text { treatment }\end{array}$ & $10 / 66$ (I5.2\%) & $32 / 66$ (48.5\%) & $38 / 69$ (55.1\%) & $70 / 135$ (51.9\%) & \\
\hline & & $\begin{array}{l}\text { Without MTX } \\
\text { treatment }\end{array}$ & $6 / 80(7.5 \%)$ & $51 / 79(64.6 \%)$ & $55 / 80(68.8 \%)$ & 106/159 (66.7\%) & \\
\hline & Ritchlin et $\mathrm{al}^{27}$ & All patients & $4 / 80(5.0 \%)$ & $4 \mathrm{I} / 80$ (5I.3\%) & 45/8I (55.6\%) & $86 / 161$ (53.4\%) & $\begin{array}{l}<0.001 \text { for all comparisons } \\
\text { versus placebo }\end{array}$ \\
\hline & & $\begin{array}{l}\text { With MTX } \\
\text { treatment }\end{array}$ & $3 / 29(10.3 \%)$ & 19/39 (48.7\%) & $22 / 39(56.4 \%)$ & $4 \mathrm{I} / 78(52.6 \%)$ & \\
\hline & & $\begin{array}{l}\text { Without MTX } \\
\text { treatment }\end{array}$ & I/5 I (2.0\%) & 22/4I (53.7\%) & $23 / 42(54.8 \%)$ & $45 / 83(54.2 \%)$ & \\
\hline
\end{tabular}

Abbreviations: ACR, American College of Rheumatology; PASI, Psoriasis Area and Severity Index; MTX, methotrexate.

An American College of Rheumatology (ACR) 20 response $\left(20 \%\right.$ or greater improvement in arthritis $\left.{ }^{28}\right)$ at week 12 was defined as the primary end point of the study.

After 12 weeks, ACR 20 was observed in $42.1 \%$ of ustekinumab treated patients versus $14.3 \%$ of patients who received placebo. At week 36, 34\% of patients in the ustekinumabtreated group, who had not received the drug for 33 weeks, still showed ACR 20. ACR 20 was also observed in 51\% (week 24), 45\% (week 28), and 42\% (week 36) of patients treated with placebo followed by ustekinumab. ACR 50 and ACR 70 were achieved in $25 \%$ and $11 \%$ of ustekinumabtreated patients, compared to $7 \%$ and 0 in the placebo group, respectively. Additionally, the ustekinumab group showed a significantly larger decrease from baseline in the Health
Assessment Questionnaire Disability Index (HAQ-DI) than the placebo group at week $12(-0.25$ [interquartile range -0.50 to 0 ] versus 0 [interquartile range -0.25 to 0.13 ], respectively).

Moreover, PASI scores were assessed in patients with psoriatic lesions affecting 3\% or more of their body surface area. At week 12, PASI 75 was achieved in 52\% of the ustekinumab-treated group and $5 \%$ of the placebotreated group. Among this cohort of patients, Dermatology Life Quality Index (DLQI) data showed a significantly greater median decrease from baseline in ustekinumabtreated patients than in placebo-treated patients at week 12 ( -6.0 [interquartile range -14.0 to -3.0 ] versus 0 [interquartile range -4.0 to 2.0 ], respectively). This study 
demonstrated the superior efficacy of ustekinumab compared to placebo in improving the signs and symptoms of PsA as well as skin psoriatic lesions.

The two Phase III studies for PsA treatment - PSUMMIT (Study of the Safety and Effectiveness of Ustekinumab in Patients with Psoriatic Arthritis) $1^{26}$ and PSUMMIT $2^{27}$ - were multicenter, randomized, double-blind, placebo-controlled trials that assessed the efficacy and safety of ustekinumab in large populations of PsA patients.

In PSUMMIT 1, 1,174 patients were screened, and 615 eligible patients with active PsA were randomly assigned to treatment groups. The patient population was from 14 countries in North America, Europe, and the Asia-Pacific region. The patients were included if they had at least five swollen joints, at least five tender joints, $\mathrm{CRP} \geq 3 \mathrm{mg} / \mathrm{L}$, and an active or past history of plaque psoriasis. Patients were randomly grouped to receive either subcutaneous ustekinumab $45 \mathrm{mg}$, subcutaneous ustekinumab $90 \mathrm{mg}$, or placebo at weeks 0 and 4 , and every 12 weeks thereafter. Patients were evaluated at week 16, and those with less than 5\% improvement in tender and swollen joint count were switched to another treatment arm: patients receiving placebo entered the ustekinumab $45 \mathrm{mg}$ group, and patients treated with ustekinumab $45 \mathrm{mg}$ entered the ustekinumab $90 \mathrm{mg}$ group. Finally, all patients who remained in the placebo group received ustekinumab $45 \mathrm{mg}$ at weeks 24 and 28, and then every 12 weeks thereafter. The primary end point of the study was defined as ACR 20 at week 24 . The secondary end points at week 24 were ACR 50 and ACR 70, PASI 75, 28-joint Disease Activity Score based on CRP (DAS28-CRP), Bath Ankylosing Spondylitis Disease Activity Index (BASDAI), HAQ-DI, 36-item Short-Form Health Survey (SF-36), and DLQI scores.

The patients in the ustekinumab $45 \mathrm{mg}$ group and $90 \mathrm{mg}$ group had significantly higher rates of ACR 20 response (42.4\% and $49.5 \%$, respectively) than the patients in the placebo group (22.8\%) at week 24 . The authors also reported significant differences at week 24 for ACR 50. An ACR 50 response was achieved in $24.9 \%$ of patients in the ustekinumab $45 \mathrm{mg}$ group, $27.9 \%$ of patients in the ustekinumab $90 \mathrm{mg}$ group, and $8.7 \%$ of patients in the placebo group ( $P<0.0001$ for all ustekinumab versus placebo comparisons). The same trend was observed for ACR 70: $12.2 \%$ of ustekinumab $45 \mathrm{mg}$ patients, $14.2 \%$ of ustekinumab $90 \mathrm{mg}$ patients, and $2.4 \%$ of placebo patients ( $P=0.0001$ for $45 \mathrm{mg}$ group versus placebo, and $P<0.0001$ for $90 \mathrm{mg}$ group versus placebo). While only $11.0 \%$ of patients in the placebo-treated group had a PASI 75 response, $57.2 \%$ and $62.4 \%$ of patients in the $45 \mathrm{mg}$ and $90 \mathrm{mg}$ ustekinumab groups achieved a PASI 75 response. Notably, the results were irrespective of concurrent methotrexate therapy. Additionally, ustekinumab appeared to be more efficacious than placebo when DAS28-CRP, BASDAI 20, and quality-of-life measures such as HAQ-DI, SF-36, and DLQI were taken into consideration. PSUMMIT 1 also reported clinically important and statistically significant results regarding the effect of ustekinumab on patients with enthesitis or dactylitis. At week 24, enthesitis was present in $68.6 \%$ and $60.8 \%$ of patients in the ustekinumab $45 \mathrm{mg}$ and $90 \mathrm{mg}$ groups, respectively, compared to $81.0 \%$ of patients in the placebo group. Similar results were noted when patients were examined for dactylitis $(56.6 \%, 55.8 \%$, and $76.1 \%$, respectively). At present, TNF $\alpha$ blockers are the only FDAapproved drugs for these conditions. The promising efficacy of ustekinumab on dactylitis and enthesitis in addition to spondyloarthritis may provide a further therapeutic option for these patients. ${ }^{29}$

Ustekinumab also showed an efficacious effect in placebotreated patients after switching to ustekinumab. Among 120 patients that began receiving ustekinumab at week 24 , ACR 20 scores were achieved in $65.2 \%$ by week 52, a comparable result to the other treatment groups. Similarly, PASI 75 response was reached in $67.7 \%$ of patients in the placebo group that crossed over at week 24 , compared to $68.1 \%$ of patients in the ustekinumab $90 \mathrm{mg}$ group $(P>0.05)$. Other outcome measures, such as ACR 50, ACR 70, quality-of-life measures, and skin indices, showed the same trend at week 52. It is important to consider the fact that this trial was not placebo-controlled beyond 24 weeks. Therefore, the results beyond this time point should be interpreted cautiously.

In PSUMMIT 2, 312 patients with PsA were randomly assigned to be treated with $45 \mathrm{mg}$ or $90 \mathrm{mg}$ ustekinumab or a placebo. Patients were randomized using a stratified central randomization method. Similar to PSUMMIT 1, the treatments occurred at weeks 0,4 , and every 12 weeks thereafter. The PsA patients were required to have active PsA for at least 6 months. The eligible patients on other treatments also had a minimum refractory period to other treatments, including disease-modifying antirheumatic drugs, (3 months), non-steroidal anti-inflammatory drugs (4 weeks), etanercept, adalimumab, golimumab, or certolizumab pegol (8 weeks), or infliximab or other TNF antagonists (14 weeks). Concurrent methotrexate therapy was allowed if started more than 3 months before commencement of the trial and if at a stable dose of $\leq 25 \mathrm{mg} /$ week for at least 4 weeks. Patients who had less than 5\% improvement in their joint symptoms entered a "blinded early escape" at week 16 . This protocol involved patients receiving placebo switching to ustekinumab $45 \mathrm{mg}$, 
those receiving ustekinumab $45 \mathrm{mg}$ switching to ustekinumab $90 \mathrm{mg}$, and patients receiving ustekinumab $90 \mathrm{mg}$ continuing with blinded $90 \mathrm{mg}$ dosing. Placebo-treated patients who did not start the early escape crossed over to receive ustekinumab $45 \mathrm{mg}$ at week 24 and thereafter. The primary end point of this trial was the same as for PSUMMIT 1, and included ACR 20 at week 24. Other end points included PASI score, DAS28-CRP less than 2.6, DLQI, SF-36, 0.3 or more unit improvement in HAQ-DI, presence of dactylitis, entheseal tenderness or pain using the PsA-modified Maastricht Ankylosing Spondylitis Enthesitis Score 24, BASDAI, and level of fatigue using the 13-item Functional Assessment of Chronic Illness Therapy Fatigue (FACIT-Fatigue) questionnaire.

The ACR 20 response for PSUMMIT 2 at week 24 was very similar in the $45 \mathrm{mg}$ and the $90 \mathrm{mg}$ ustekinumab groups (43.7\% and 43.8\%, respectively). Both doses achieved a significantly higher response rate when compared to the placebo group $(20.2 \%, P<0.001$ compared to either ustekinumabtreatment groups). The number of patients who achieved DAS28-CRP response was comparable in both of the ustekinumab groups, with a cumulative response of $53.8 \%$, and both were significantly higher than the placebo group, with a $29.8 \%$ response. PASI 75 response was achieved in a higher proportion of the ustekinumab-treated than placebo-treated patients at week 24, and all comparisons showed statistically significant efficacy (Table 1), irrespective of the status of methotrexate therapy or body weight. All the quality-oflife measures (HAQ-DI score, FACIT-Fatigue score, DLQI score, and SF-36 score) were significantly improved in both ustekinumab groups versus the placebo group, except the mental component of SF-36, which was comparable between all groups at week 24. Patients with enthesitis and dactylitis responded better to both ustekinumab groups than the placebo group. However, this improvement only reached statistical significance in patients with enthesitis.

Among those patients who received methotrexate, an ACR 20 response was achieved at week 24 in $35.6 \%$ of patients in the combined ustekinumab groups versus $14.5 \%$ of patients in the placebo group $(P<0.01)$. The PASI 75 response was even more apparent in the combined ustekinumab groups compared to the placebo group among the same subgroup of patients $(47.1 \%$ versus $2.0 \%, P<0.01)$. Among patients who were on TNF $\alpha$ inhibitors, median changes in HAQ-DI scores were significantly more pronounced $(-0.13$, interquartile range -0.38 to 0$)$ in the combined ustekinumab groups than the placebo-treatment group (0, interquartile range -0.13 to 0.13$)(P<0.05)$.

In a recent updated report of PSUMMIT 1 and PSUMMIT 2, Kavanaugh et al showed that both ustekinumab $45 \mathrm{mg}$ and ustekinumab $90 \mathrm{mg}$ can provide a sustained inhibition of radiographic progression of joint damage, and this effect was significantly higher than the placebo group. The PsA-modified van der Heijde-Sharp score was used to evaluate hand or foot radiographs to monitor the progression of joint involvement. The placebo group had a

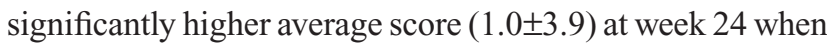
compared to the ustekinumab $45 \mathrm{mg}(0.4 \pm 2.1)$ and $90 \mathrm{mg}$ groups $(0.4 \pm 2.4) .{ }^{30}$

\section{Safety}

The safety profile of ustekinumab has been extensively examined for the treatment of psoriasis as well as PsA. The Phase III multicenter PSUMMIT 1, which administered treatment of $45 \mathrm{mg}$ ustekinumab, $90 \mathrm{mg}$ ustekinumab, or placebo for 52 weeks, demonstrated a $42 \%$ rate by week 16 and $49.5 \%$ by week 24 of at least one adverse event (AE) occurring in the combined ustekinumab-treatment groups. ${ }^{26}$ The most common AEs of the combined ustekinumab-treatment groups for psoriasis were respiratory tract infections, headaches, arthralgia, and nasopharyngitis. There was a combined $1.7 \%$ rate of serious AEs, with consequent discontinuation of treatment in six patients. ${ }^{26}$

In a randomized clinical study of 146 patients with PsA treated with ustekinumab, the treatment was reasonably well tolerated. ${ }^{25}$ Patients were administered a $63 \mathrm{mg}$ or $90 \mathrm{mg}$ dose of ustekinumab or a placebo. By 12 weeks of treatment, $61 \%$ of the patients in the combined treatment groups and $63 \%$ of the patients in the placebo group had one or more AEs, suggesting that ustekinumab was well tolerated compared to placebo. By week 36, the treatment group had 76\% of participants with an AE compared to $63 \%$ of the patients treated with placebo followed by ustekinumab. ${ }^{25}$ Similar to ustekinumab treatment for psoriasis, the majority of AEs were upper respiratory tract infections or nasopharyngitis.

In PSUMMIT 1, 615 adult PsA patients were randomized to receive $45 \mathrm{mg} / 90 \mathrm{mg} /$ placebo treatment and were followed for 2 years. ${ }^{31}$ The placebo-treated patients began $45 \mathrm{mg}$ ustekinumab therapy at week 24 . A total of 490 of the participants completed the study, with $5 \%$ of the participants discontinuing due to serious AEs. The rates (per 100 patientyears of follow-up) of serious infections, malignancies, and major adverse cardiovascular events were 1.23, 0.38, and 0.66 , respectively, in the ustekinumab-treated groups when combined. $^{31}$

In PSUMMIT 2, with 312 patients with PsA, ustekinumab was administered at doses of $45 \mathrm{mg}$ or $90 \mathrm{mg}$ or a placebo, with the placebo group crossing over to $45 \mathrm{mg}$ 
ustekinumab at 24 weeks. ${ }^{27}$ After 16 weeks of treatment, the combined ustekinumab-treatment group had AEs in $61.8 \%$ of the patient population compared to $54.8 \%$ in the placebo group. These data suggest that ustekinumab is reasonably well tolerated. Even at 24 weeks, the combined ustekinumab group showed $66.4 \%$ of the patients having an AE compared to $63.5 \%$ for the placebo group. ${ }^{27}$ The majority of AEs were similar to those found in psoriatic patients, with nasopharyngitis and upper respiratory tract infections as the most common.

A study aggregating the results from a Phase II study, ${ }^{25}$ PSUMMIT 1, and PSUMMIT 2 results included 1,071 treated patients with PsA. ${ }^{32}$ The placebo-treated group had 348.07 AEs per 100 patient-years compared to 375.83 for ustekinumab-treated patients in the PsA-specific studies. Furthermore, the placebo group had 12.69 serious AEs compared to 5.75 for the ustekinumab-treated group per 100 patient-years. Results from psoriasis studies with PsA patient subgroups reported similar levels of AEs of 476.42 for the placebo and 481.31 for the ustekinumab-treated groups (events per 100 patient-years). ${ }^{32}$

Aggregated data from a Phase II study, ${ }^{20}$ PHOENIX 1, PHOENIX 2, and ACCEPT included 3,117 patients totaling 8,998 patient years of follow-up and compared the safety of ustekinumab $45 \mathrm{mg}$ or $90 \mathrm{mg}$ treatment in psoriatic patients to the PsA subgroup. ${ }^{33}$ Of the 858 patients with PsA totaling 2,490 years of patient follow-up, there were 249.40 AEs per 100 patient-years compared to 232.59 AEs per 100 patientyears for the overall population. Among the AEs, the rate of major adverse cardiovascular events and serious infections for the PsA group was $0.56 / 100$ patient-years and $1.53 / 100$ patient-years compared to $0.44 / 100$ patient-years and $1.10 / 100$ patient-years in the overall population. ${ }^{33}$ Therefore, ustekinumab treatment for PsA appears to have comparable results to the overall treated psoriasis population.

There has been extensive research on the safety profile of ustekinumab for the treatment of psoriasis and PsA, and it appears that long-term treatment with ustekinumab does not alter the risks associated with its use. Furthermore, there are no dose-dependent risks associated with ustekinumab use. The safety of ustekinumab is comparable to other approved drugs for the treatment of psoriasis and PsA.

\section{Conclusion}

The current literature supports the efficacy and safety of ustekinumab in the treatment of PsA. The results from Phase III trials suggest that ustekinumab is also useful for treating enthesitis, dactylitis, and spondyloarthrosis. Furthermore, data from the PSUMMIT trials suggest that the onset of action is slower with ustekinumab than TNF $\alpha$ inhibitors, although a similar efficacy rate can be achieved by 52 weeks. Future trials comparing these two classes of drugs are essential to further elucidate their relative efficacy. ${ }^{29}$

\section{Disclosure}

The authors report no conflicts of interest in this work.

\section{References}

1. Zachariae H, Zachariae R, Blomqvist $\mathrm{K}$, et al. Quality of life and prevalence of arthritis reported by 5,795 members of the Nordic Psoriasis Associations. Data from the Nordic Quality of Life Study. Acta Derm Venereol. 2002;82(2):108-113.

2. Gelfand JM, Gladman DD, Mease PJ, et al. Epidemiology of psoriatic arthritis in the population of the United States. J Am Acad of Dermatol. 2005;53(4):573.

3. Radtke MA, Reich K, Blome C, Rustenbach S, Augustin M. Prevalence and clinical features of psoriatic arthritis and joint complaints in 2009 patients with psoriasis: results of a German national survey. $J$ Eur Acad Dermatol Venereol. 2009;23(6):683-691.

4. Moll J. Psoriatic arthropathy. In: Mier P, van de Kerkhof P, editors. Textbook of Dermatology. Edinburgh: Churchill Livingstone; 1986: $55-82$.

5. Saad AA, Symmons DP, Noyce PR, Ashcroft DM. Risks and benefits of tumor necrosis factor-alpha inhibitors in the management of psoriatic arthritis: systematic review and metaanalysis of randomized controlled trials. J Rheumatol. 2008;35(5):883-890.

6. Goulabchand R, Mouterde G, Barnetche T, Lukas C, Morel J, Combe B. Effect of tumour necrosis factor blockers on radiographic progression of psoriatic arthritis: a systematic review and meta-analysis of randomised controlled trials. Ann Rheum Dis. 2014;73(2):414-419.

7. Janssen Biotech. Stelera (ustekinumab) [prescribing information]. Bloomington (IN): Janssen Biotech; 2012. Available from: http:// www.stelarainfo.com/pdf/PrescribingInformation.pdf. Accessed June 9, 2014.

8. Yawalkar N, Tscharner GG, Hunger RE, Hassan AS. Increased expression of IL-12p70 and IL-23 by multiple dendritic cell and macrophage subsets in plaque psoriasis. J Dermatol Sci. 2009;54(2):99-105.

9. Murphy KM, Reiner SL. The lineage decisions of helper T cells. Nat Rev Immunol. 2002;2(12):933-944.

10. Langrish CL, Chen Y, Blumenschein WM, et al. IL-23 drives a pathogenic $\mathrm{T}$ cell population that induces autoimmune inflammation. J Exp Med. 2005;201(2):233-240.

11. Harrington LE, Hatton RD, Mangan PR, et al. Interleukin 17-producing CD4+ effector T cells develop via a lineage distinct from the $\mathrm{T}$ helper type 1 and 2 lineages. Nat Immunol. 2005;6(11):1123-1132.

12. Di Cesare A, Di Meglio P, Nestle FO. The IL-23/Th17 axis in the immunopathogenesis of psoriasis. J Invest Dermatol. 2009;129(6): 1339-1350.

13. Lowes MA, Kikuchi T, Fuentes-Duculan J, et al. Psoriasis vulgaris lesions contain discrete populations of Th1 and Th17 T cells. J Invest Dermatol. 2008;128(5):1207-1211.

14. Filer C, Ho P, Smith RL, et al. Investigation of association of the IL12B and IL23R genes with psoriatic arthritis. Arthritis Rheum. 2008;58(12): 3705-3709.

15. Hebert HL, Ali FR, Bowes J, Griffiths CE, Barton A, Warren RB. Genetic susceptibility to psoriasis and psoriatic arthritis: implications for therapy. Br J Dermatol. 2012;166(3):474-482.

16. Zhu YW, Mendelsohn A, Pendley C, Davis HM, Zhou H. Population pharmacokinetics of ustekinumab in patients with active psoriatic arthritis. Int J Clin Pharmacol Ther. 2010;48(12):830-846. 
17. Hsu L, Armstrong AW. Anti-drug antibodies in psoriasis: a critical evaluation of clinical significance and impact on treatment response. Expert Review Clin Immunol. 2013;9(10):949-958.

18. Kauffman CL, Aria N, Toichi E, et al. A phase I study evaluating the safety, pharmacokinetics, and clinical response of a human IL-12 p40 antibody in subjects with plaque psoriasis. $J$ Invest Dermatol. 2004;123(6):1037-1044.

19. Gottlieb AB, Cooper KD, McCormick TS, et al. A phase 1, double-blind, placebo-controlled study evaluating single subcutaneous administrations of a human interleukin-12/23 monoclonal antibody in subjects with plaque psoriasis. Curr Med Res Opin. 2007;23(5):1081-1092.

20. Krueger GG, Langley RG, Leonardi C, et al. A human interleukin-12/23 monoclonal antibody for the treatment of psoriasis. $N$ Engl J Med. 2007;356(6):580-592.

21. Leonardi CL, Kimball AB, Papp KA, et al. Efficacy and safety of ustekinumab, a human interleukin-12/23 monoclonal antibody, in patients with psoriasis: 76-week results from a randomised, double-blind, placebocontrolled trial (PHOENIX 1). Lancet. 2008;371(9625):1665-1674.

22. Papp KA, Langley RG, Lebwohl M, et al. Efficacy and safety of ustekinumab, a human interleukin-12/23 monoclonal antibody, in patients with psoriasis: 52-week results from a randomised, double-blind, placebocontrolled trial (PHOENIX 2). Lancet. 2008;371(9625):1675-1684.

23. Griffiths CE, Strober BE, van de Kerkhof P, et al. Comparison of ustekinumab and etanercept for moderate-to-severe psoriasis. $N$ Engl J Med. 2010;362(2):118-128.

24. Tsai TF, Ho JC, Song M, et al. Efficacy and safety of ustekinumab for the treatment of moderate-to-severe psoriasis: a phase III, randomized, placebo-controlled trial in Taiwanese and Korean patients (PEARL). J Dermatol Sci. 2011;63(3):154-163.

25. Gottlieb A, Menter A, Mendelsohn A, et al. Ustekinumab, a human interleukin 12/23 monoclonal antibody, for psoriatic arthritis: randomised, double-blind, placebo-controlled, crossover trial. Lancet. 2009;373(9664):633-640.

26. McInnes IB, Kavanaugh A, Gottlieb AB, et al. Efficacy and safety of ustekinumab in patients with active psoriatic arthritis: 1 year results of the phase 3, multicentre, double-blind, placebo-controlled PSUMMIT 1 trial. Lancet. 2013;382(9894):780-789.
27. Ritchlin C, Rahman P, Kavanaugh A, et al. Efficacy and safety of the anti-IL-12/23 p40 monoclonal antibody, ustekinumab, in patients with active psoriatic arthritis despite conventional non-biological and biological anti-tumour necrosis factor therapy: 6-month and 1-year results of the phase 3 , multicentre, double-blind, placebocontrolled, randomised PSUMMIT 2 trial. Ann Rheum Dis. 2014;73(6): 990-999.

28. Felson DT, Anderson JJ, Boers M, et al. American College of Rheumatology. Preliminary definition of improvement in rheumatoid arthritis. Arthritis Rheum. 1995;38(6):727-735.

29. Warren RB, Chinoy H. Ustekinumab for psoriatic arthritis: close to the PSUMMIT? Lancet. 2013;382(9894):748-749.

30. Kavanaugh A, Ritchlin C, Rahman P, et al. Ustekinumab, an anti-IL-12/23 p40 monoclonal antibody, inhibits radiographic progression in patients with active psoriatic arthritis: results of an integrated analysis of radiographic data from the phase 3, multicentre, randomised, double-blind, placebo-controlled PSUMMIT-1 and PSUMMIT-2 trials. Ann Rheum Dis. 2014;73(6):1000-1006.

31. Kavanaugh A, Gottlieb AB, Ritchlin CT, et al. Efficacy and safety of ustekinumab in patients with active psoriatic arthritis: 2-year results from a phase 3, multicenter, double-blind, placebo-controlled study. Poster presented at: 2013 ACR/ARHP Annual Meeting; October 26-30, 2013; San Diego.

32. McInnes IB, Papp K, Puig, L, et al. Safety of ustekinumab from the placebo-controlled periods of psoriatic arthritis and psoriasis clinical developmental programs. Poster presented at: 2013 ACR/ARHP Annual Meeting; October 26-30, 2013; San Diego.

33. Papp KA, Griffiths CE, Gordon K, et al. Long-term safety of ustekinumab: 5 years of follow-up from the psoriasis clinical development program including patients with psoriatic arthritis. Poster presented at: 2013 ACR/ARHP Annual Meeting; October 26-30, 2013; San Diego.
Clinical, Cosmetic and Investigational Dermatology

\section{Publish your work in this journal}

Clinical, Cosmetic and Investigational Dermatology is an international, peer-reviewed, open access, online journal that focuses on the latest clinical and experimental research in all aspects of skin disease and cosmetic interventions. All areas of dermatology will be covered; contributions will be welcomed from all clinicians and

\section{Dovepress}

basic science researchers globally. This journal is indexed on CAS. The manuscript management system is completely online and includes a very quick and fair peer-review system, which is all easy to use. Visit http://www.dovepress.com/testimonials.php to read real quotes from published authors. 